\title{
A LIMITAÇÃO DO DANO MORAL NA JUSTIÇA DO TRABALHO COMO UMA AFRONTA AO PRINCÍPIO DA DIGNIDADE DA PESSOA HUMANA DO TRABALHADOR
}

\author{
Luciana Aboim Machado Gonçalves da Silva* \\ Rebecca Falcão Viana Alves**
}

RESUMO: O presente trabalho analisa a limitação dos danos morais do trabalhador com vistas ao princípio da dignidade da pessoa humana. A fim de obter respostas para tal dúvida foi necessário tratar sobre o conceito de dignidade da pessoa humana e a sua relação com os direitos humanos. Também se adentrou no sentido do dano moral e da lesão aos direitos da personalidade, para se auferir reflexões sobre as novas regras que a reforma trabalhista estabeleceu sobre esta temática. Para tal finalidade, a metodologia utilizada foi a de pesquisa bibliográfica baseada na normatização jurídica, a par de doutrinas especializadas.

PALAVRAS-CHAVES: Reforma Trabalhista; Dano Extrapatrimonial; Dignidade da Pessoa Humana; Direitos Humanos; Justiça Trabalhista.

\section{THE LIMITATION OF MORAL DAMAGE IN LABOUR COURTS AS A OFFENSE AGAINST THE PRINCIPEL OF HUMAN DIGNITY OF THE WORKER}

\begin{abstract}
The present research analyzes if the limitation of the moral damages of the employee offends the principle of the human dignity. Therefore, It was necessary to conceptualize moral damage and human dignity to understand what was their relationships with human rights. Also, it compared the civil moral damage against the new rules of moral damages in labor law, in order to analyze whether there was a reduction in the right to moral indemnity to workes. For this purpose, the methodology used was the one of bibliographical search based on doctrine and on the labor law and the civil code.
\end{abstract}

KEYWORDS: Labour Law Reform Bill; Moral Damage; Human Dignity; Human Rights; Labour Courts.

\footnotetext{
* Professora Associada da Universidade Federal de Sergipe. Pós-Doutora em Direito pela Universidade Federal da Bahia e pela Università Degli Studi G. d'Annunzio. Doutora em Direito do Trabalho pela USP. Mestre em Direito do Trabalho e especialista em Direito do Trabalho e Direito Processual Civil pela PUC/SP. Vicepreisdente da Associación Iberoamericana de Derecho del Trabajo y de la Seguridad Social. Líder do Grupo de Pesquisa Eficácia dos Direitos Humanos e seus reflexos nas relações sociais (www.gedhufs.com). E-mail: lucianaaboim@gmail.com

** Mestranda em Direito pelo Programa de Pós-Graduação em Direito da Universidade Federal de Sergipe. Bolsista da CAPES. Especializa em Direito do Trabalho e Previdenciário pela Faculdade Guanambi. E-mail: rebecca.f.v.alves@gmail.com
}

Rev. de Direito do Trabalho e Meio Ambiente do Trabalho | e-ISSN: 2525-9857 | Porto Alegre | v. 4 | n. 2 | p. 156 - 173 | Jul/Dez. 2018 


\section{INTRODUÇÃO}

Em 1948, a Declaração Universal de Direitos Humanos foi publicada como uma resposta aos horrores cometidos na Segunda Guerra Mundial. A guerra foi a responsável por trazer às nações mundiais a compreensão de que os indivíduos precisavam de proteção contra as barbáries cometidas aos cidadãos em diversas nações.

Desde então, os Direitos Humanos vêm evoluindo constantemente, ganhando prestígio e força nos ordenamentos jurídicos internos, passando a serem direitos fundamentais, e no ordenamento jurídico internacional, como direitos humanos.

Os Direitos Humanos e Fundamentais formam um conjunto de direitos mínimos e essenciais para que se possa ter uma vida digna. Em verdade, é visível que o seu alicerce mais poderoso é o princípio da Dignidade da Pessoa Humana, brocardo basilar da ordem jurídica brasileira, garantido que todos possam ter uma existência digna, ou seja, existência plena com seus direitos respeitados.

Para que haja a sua máxima eficácia, os Direitos Humanos e Fundamentais precisam estar num patamar hierarquicamente superior e, ao mesmo tempo, entrelaçado com as demais searas do Direito que compõem a normatização de um país. Por tal motivo, é importante observar se todas as searas do Direito estão atentando às premissas dos direitos humanos e fundamentais imersos em tratados internacionais e no ordenamento constitucional pátrio.

Recentemente, em 2017, foi publicada a Lei n. 13.467/17, que trata sobre a reforma trabalhista. Desde as primeiras votações no Congresso Nacional, a citada lei gerou vários embates, especialmente, por alegarem que ela não está de acordo com os preceitos do sistema internacional de direitos humanos e do ordenamento jurídico brasileiro.

No meio de seu texto, a reforma trabalhista de 2017 trouxe, dentre diversas mudanças, novas regras sobre danos extrapatrimoniais na Justiça do Trabalho, ensejando diversos questionamentos para os operadores do Direito do Trabalho.

Por este motivo, o presente artigo visa estudar a lei referente à reforma trabalhista, Lei n. 13.467/17, a fim de compreender se a mudança no dano extrapatrimonial na relação de trabalho está de fato afrontando o princípio da dignidade da pessoa humana ao criar limites de indenização e diferenciar tratamento dos trabalhadores que recebam salários diferentes.

Para tanto, o estudo pretende se guiar pelas seguintes perguntas: O que é Dignidade da Pessoa Humana? Qual a sua relação com os Direitos Humanos e Fundamentais? O que é o 
dano moral? Qual o impacto da reforma trabalhista no âmbito do dano moral para os trabalhadores? A mudança do dano extrapatrimonial afeta a Dignidade Humana?

Com o objetivo de compreender se o tratamento diferenciado de valores entre o dano moral de um cidadão enquanto empregado em uma relação de trabalho e o dano moral de cidadão fora da relação de trabalho é realmente uma afronta à dignidade humana uma vez que não há justo motivo para que essa discriminação aconteça.

Por fim, para a realização desta pesquisa, a metodologia utilizada foi, primeiramente, o levantamento bibliográfico acerca dos conceitos de dano moral, dignidade humana e direitos humanos; logo após foi feita a pesquisa documental, sendo utilizadas fontes primárias como tratados internacionais e normas jurídicas brasileiras, especialmente, a Constituição Federal, a lei que instituiu a reforma trabalhista e o Código Civil.

\section{A DIGNIDADE DA PESSOA HUMANA E SUA RELAÇÃO COM OS DIREITOS HUMANOS}

Os direitos humanos são aqueles necessários para se viver dignamente. Para Ramos (2018, p. 29) "Os direitos humanos consistem em um conjunto de direitos considerados indispensável para uma vida humana pautada na liberdade, igualdade e dignidade."

Na visão crítica de Herrera Flores (2009, p. 28), os direitos humanos são “[...] o resultado sempre provisório das lutas que os seres humanos colocam em prática para ter acesso aos bens necessários para a vida."

Com a Declaração Universal dos Direitos Humanos - DUDH (1948) se consagrou a universalização dos direitos humanos e a importância do princípio da dignidade da pessoa humana, ao se estabelecer, no preâmbulo o reconhecimento da dignidade inerente a todos os membros da sociedade.

O objetivo da DUDH é, de acordo com Piovesan (2013, p. 196), “delinear uma ordem pública mundial fundada no respeito à dignidade humana, ao consagrar valores básicos universais.".

Piovesan (2017, p. 50) ainda aduz que os Direitos Humanos constituem “[...] uma plataforma emancipatória voltada à proteção da dignidade humana.”. Vê-se que a relação entre os Direitos Humanos e o princípio da Dignidade da Pessoa Humana é inerente, a ponto 
de um ser base para o outro. E mais, há uma “[...] tendencial elevação da dignidade humana a pressuposto ineliminável de todos os constitucionalismos." (PIOVESAN, 2017, p. 53).

Dessa forma, a dignidade se constitui em um valor existencial que é imputado a alguém apenas pelo simples fato de que é um ser humano. A importância do princípio da dignidade da pessoa humana para o ordenamento jurídico brasileiro é enorme; a Constituição o traz como um dos princípios fundamentais da República Federativa do Brasil, ou seja, como uma das bases para a criação não só do ordenamento jurídico como da própria identidade do país. Conforme Barroso (2010), a dignidade da pessoa humana reúne valores civilizatórios que são incorporados ao patrimônio da humanidade.

Consagrando a natureza essencial de certos direitos, a Constituição Brasileira, norma suprema de nosso país, dedica a sua parte introdutória aos Direitos Fundamentais, servindo de fonte e base interpretativa do sistema jurídico brasileiro.

Nesse sentido, SCARLET (2015, p. 71) aduz: “[...] os direitos fundamentais são, em verdade, concretizações do princípio fundamental da dignidade da pessoa humana, consagrado expressamente em nossa Lei Fundamental". Ademais, registra que são "resultados da luta histórica pela afirmação do princípio da dignidade da pessoa humana, que constitui o núcleo essencial de todas as reivindicações [...]”. (Ibidem, p. 73).

Assim, o princípio da dignidade da pessoa humana é a base pela qual não apenas se fundamenta, mas também se luta para a criação e a sustentação dos Direitos Humanos e Direitos Fundamentais. Sendo, clara, a sua relação intrínseca com todos os ramos do Direito, extrai-se que se houver uma afronta à dignidade também se atingirá os Direitos Humanos e Fundamentais.

Além dessa visão mais ampla e genérica de que os Direitos Humanos são os direitos essenciais para todos os seres humanos, há a perspectiva de que eles se configuram em direitos subjetivos. É o que explica Hierro (2016, p. 115), “La noción misma de derechos subjetivos [...] aparece ligada a la afirmación del individuo como soberano sobre sí mismo [...]". Ou seja, sua definição de direitos subjetivos é aqueles direitos que estão ligados ao sujeito como dono de si mesmo ao mesmo tempo em que o Estado Soberano continua a governar aspectos de sua vida pública. Em outras palavras, os direitos subjetivos seriam os ligados à primeira dimensão dos direitos humanos que garantem, nessa relação, a individualização da pessoa como sujeito e mestre de seu próprio destino, tendo direitos, que podem forçar o Estado a fazer ou não fazer algo, e deveres para com o Estado também. 
Nesse caminho, Barroso (2014, p.62) explica que a dignidade humana pode ser entendida com duas dimensões "uma interna, expressa no valor intrínseco ou próprio de cada indivíduo; outra externa, representando seus direitos, aspirações e responsabilidades, assim como os correlatos deveres de terceiros." Para o autor, a primeira dimensão é inviolável, pois o valor do indivíduo jamais pode ser perdido, já que mesmo perdendo a própria compreensão de sua dignidade, o indivíduo não perde sua condição humana; enquanto que a segunda dimensão é passível de violação e ofensa.

Com essa individualização da pessoa que o conceito de dignidade passa a trabalhar tanto no sentido amplo de dignidade para todos, como no sentido estrito de dignidade para aquela pessoa em específico.

No âmbito do Direito Civil, a doutrina extrai do princípio da dignidade humana os direitos da personalidade que são concedidos a todos os seres humanos. Como afirma Barroso (2010), a dignidade da pessoa humana está no núcleo essencial dos direitos fundamentais e que dele se extrai a tutela de dois requisitos fundamentais para o ser humano, o mínimo existencial e a personalidade humana, que são reflexos de como tal direito tem a influência não apenas no que se relaciona à dimensão física como à moral do indivíduo.

Compreendendo que a dignidade humana é o conjunto de direitos que garantam o mínimo existencial e a sadia sobrevivência da personalidade humana; bem como entendendo que a sua relação com os Direitos Humanos e Fundamentais é intrínseca, é relevante ressaltar sobre a relação da dignidade humana com o dano moral.

\section{DANO MORAL}

O dicionário da língua portuguesa define dano como um prejuízo ou um estrago que é causado ou sofrido por algo ou por alguém; tal conceito é semelhante ao estabelecido no dicionário jurídico que, de acordo com Gonçalves (2018, p. 367): “[...] o conceito clássico de dano é o de que constitui ele uma 'diminuição do patrimônio' [...]”.

Porém, a definição tradicional é limitada; por isso, Gonçalves (2018) afirma que a melhor definição é a que envolve a noção de diminuição ou subtração de um "bem jurídico", para abranger não só o patrimônio, mas também a honra, a vida e outros direitos da personalidade que necessitam de proteção. Justamente, a ideia de que a lesão afeta o bem 
jurídico tutelado e não apenas o patrimônio é que permite a existência do dano exclusivamente moral, ou seja, aquele que não afete diretamente a um objeto físico.

Em consonância com o pensamento de Gonçalves de que o dano não pode atingir apenas os bem patrimoniais tem o entendimento de Miragem (2015, p. 155), o qual afirma que "é uma lesão a um bem juridicamente protegido".

Para Tartuce (2018, p. 417) os danos morais são “[...] uma lesão aos direitos da personalidade (art. 11 a 21 do CC); para sua reparação não se requer a determinação de um preço para a dor ou sofrimento, mas sim um meio para atenuar, em parte, as consequências do prejuízo imaterial [...]”.

Destarte, o dano moral é aquele dano que atinge a alma do indivíduo, ferindo seus direitos da personalidade como sua honra, imagem, intimidade etc. Em outras palavras, o dano moral é aquele que afeta negativamente os direitos da personalidade. Considerando que a dignidade humana embasa os direitos da personalidade, extrai-se a relação entre ambos.

É corrente a conceituação doutrinária de que o dano moral é aquele que gera dor, humilhação ou sofrimento emocional e psicológico para o lesado ao violar um de seus direitos da personalidade. Todavia, é válido frisar que o dano moral não é a dor causada; essa dor é consequência do dano moral, o dano é o ato lesivo contra os direitos da personalidade, que se extrai do princípio da dignidade da pessoa humana.

Nesse sentido, diz a jurista espanhola Díaz (2016, p.9) "Se bien no se pude considerar que los daños morales presenten un aspecto económico o valuable preciso, esto no impide que exista una obrigación de su indemnización.”. Ou seja, o dano aos direitos da personalidade em si não possui valor monetário, mas, sim, a indenização decorrente ação danosa.

É importante atentar que nenhuma indenização será devida se o dano não for "atual e certo". Isto porque nem todo dano é ressarcível, mas somente o que preencher os requisitos de certeza e atualidade. $\mathrm{O}$ dano certo é o que efetivamente ocorreu e que não é hipotético, nem eventual; enquanto atual é o dano que já existe no momento da ação de reparação. Ou seja, é necessário que o dano tenha acontecido; excepcionalmente, pode haver danos com efeitos futuros, desde que ele seja gerado por uma ação no presente, que seja possível mensurar razoavelmente o prejuízo que será gerado e que exista a probabilidade objetiva de que ele ocorrerá. (GONÇALVES, 2018, p. 369)

Existem diversas categorias de danos, porém o tipo de dano que o presente trabalho explora é o dano extrapatrimonial ou moral. Conforme Gonçalves (2018, p. 370) a expressão 
dano extrapatrimonial "[...] deve ser reservada exclusivamente para designar a lesão que não produz qualquer efeito patrimonial.”.

Para doutrinadores civis, como Miragem (2015), Tartuce (2018) e Gonçalves (2018), o dano extrapatrimonial engloba não apenas a categoria do dano moral, como também os danos estéticos - decorrentes de uma lesão ao físico da pessoa - e os danos existenciais - que afetam a vida em longo prazo do ofendido. A Lei n. 13.467/17 decretou que, no caso das relações trabalhistas, os danos extrapatrimoniais eram apenas os morais e os existenciais, ignorando assim os danos estéticos.

Apesar de os direitos da personalidade estarem disciplinados no Código Civil, assim como está o instituto da responsabilidade civil, o Direito do Trabalho se vale destas normas jurídicas, uma vez que o direito comum é fonte subsidiária - antes da reforma, aplicava-se apenas as normas civilistas no que não era incompatível com seus princípios fundamentais; após a reforma, a parte que condicionava a aplicação à compatibilidade com os princípios trabalhistas foi retirada.

É necessário salientar, ademais, que um dos principais pontos de atrito da doutrina e da jurisprudência tanto civil quanto trabalhista, é a quantificação do dano moral. Diferente do dano material que tem meios de provar o prejuízo concreto, o dano moral precisa ser ponderado e arbitrado para que lhe seja dado um valor. Por ser um dano que atinge a personalidade do trabalhador, este valor se torna verdadeiramente difícil de ser quantificado. Porém, como pode se observar no seguinte fragmento de texto, a doutrina e a jurisprudência sempre tentaram criar critérios objetivos para ajudar na fixação do valor:

Pois bem, na estreita da doutrina e da jurisprudência, na fixação de indenização por
danos morais, o magistrado deve agir com equidade, analisando: a extensão do dano;
as condições socioeconômicas e culturais dos envolvidos, as condições psicológicas
das partes, o grau de culpa do agente, de terceiro ou da vítima. (TARTUCE, 2018, p.
447)

Outro ponto interessante de ser relevar é o que trata sobre a tarifação, ou também conhecida como limite prévio, dos danos morais. Para a parte massiva da doutrina civil Miragem, Tartuce, Gonçalves, dentre outros - essa tarifação não foi recebida pela Constituição Federal de 1988 e pelo Código Civil de 2002, que trazem a ideia de reparação integral e proporcional ao dano.

Consoante as palavras de Gonçalves (2018, p. 48) "Não tem aplicação, em nosso país, o critério da tarifação, pelo qual o quantum das indenizações é prefixado.” Além deste fato, o doutrinador ainda aduz que sabendo com antecedência a quantia máxima a ser paga o 
autor do ato lesivo pode concluir que praticar a lesão é mais vantajoso que não praticá-la. Observa-se tal argumento nesta assertiva:

O inconveniente desse critério é que, conhecendo antecipadamente o valor a ser pago, as pessoas podem avaliar as conseqüências da prática do ato ilícito e confrontá-las com as vantagens que, em contrapartida, poderão obter, como no caso do dano à imagem, e concluir que vale a penas, no caso, infringir a lei. (ibidem, p.48)

A despeito disso, como dito, a CLT foi recentemente alterada, estabelecendo a tarifação do dano extrapatrimonial nas relações de trabalho, cabendo ser examinada no próximo tópico.

\subsection{As Novas Regras para o Dano Extrapatrimonial Trabalhista}

A parte da Lei n. 13.467/17 que é apreciada por este artigo é o Título II-A, que trata sobre o dano extrapatrimonial nas relações de trabalho. Esse novo título é composto por sete artigos, que vão do 233-A ao 233-G, que foram incorporados na Consolidação das Leis Trabalhistas - CLT, suprimindo a ausência de uma regulamentação específica dos danos extrapatrimoniais nas relações de emprego.

A falta de critérios objetivos para a fixação do dano moral nas relações laborais sempre foi uma questão bastante debatida, recorrendo-se ao Direito Civil para o seu arbitramento.

A regra que o Direito Civil traz é a prevista no artigo 946 do CC, estabelecendo que na falta de uma lei ou contrato que fixe a indenização de uma obrigação indeterminada, ela será apurada através do que determinar a lei processual. Outro artigo, do mesmo código, muito utilizado para estabelecer o caráter de arbitramento dos danos morais é o artigo 953 o qual trata sobre a indenização da injúria, calúnia e difamação que consistirá na reparação do dano causado ao ofendido, enquanto que seu parágrafo único estabelece que se não houver como provar os danos materiais, o juiz arbitrará equitativamente o valor da indenização conforme as características do caso.

Em outras palavras, as regras para a fixação desde a Constituição Federal de 1988 ficaram abertas, restando para a doutrina e para os juízes a ponderação sobre quais os melhores critérios para se valorar o dano.

Para Gonçalves (2018), os critérios utilizados seriam a extensão e repercussão da ofensa, o grau de culpa do ofensor, a gravidade do dano, a intensidade do sofrimento da vítima, bem como a situação patrimonial do ofensor e do ofendido. Contudo, o último critério 
sobre a condição econômica e social do ofendido não é uma unanimidade na doutrina, apesar de ser um critério sempre utilizado.

Os critérios adotados e anteriormente citados visam cumprir as três funções do dano moral: a punitiva, a compensatória e a preventiva. A função punitiva tem por escopo responsabilizar o ofensor pelos seus atos, punindo-o por praticar um ato lesivo a outrem, com vistas ao princípio neminem leadere, ou seja, o princípio de não lesar a outro. A compensatória trata sobre a vítima, pois é por meio da indenização que irá se reparar o dano causado à vítima. Por fim, a preventiva, é a função de coibir o ofensor de repetir o ato lesivo, bem como de servir de exemplo para sociedade.

Em atenção à função preventiva e compensatória, a indenização não pode ser insignificante para o ofensor para não repetir o ato, como também não pode ser insignificante a vítima a ponto de não trazer nenhuma compensação. É dizer, a indenização não pode ser maior que a capacidade do ofensor e não pode gerar enriquecimento indevido para a vítima.

As mudanças que a reforma trabalhista trouxe nos faz analisar a temática, especialmente nos seguintes pontos: legislação aplicável; extensão da definição de dano extrapatrimonial; titularidade dos direitos tutelados; o rol dos artigos 233-C e 233-D; responsabilidade solidária com limites; a possibilidade ou não da tarifação dos danos morais e, por fim, a utilização do salário contratual como base da tarifação e o tratamento desigual. Mantendo-se a ordem já estabelecida, o primeiro ponto a se discutir é a legislação aplicável aos danos extrapatrimoniais trabalhistas.

Essa dúvida surge devido ao que o artigo 233-A da lei da reforma traz em seu bojo, qual seja, "Aplicam-se à reparação de danos de natureza extrapatrimonial decorrentes da relação de trabalho apenas os dispositivos deste Título." (BRASIL, 2017). A questão que se tem suscitado dúvidas é sobre a palavra "apenas", que o artigo traz.

Para Delgado e Delgado (2017, p.145) este artigo é uma tentativa “[...] de isolar a nova regência normativa inserida no Título II-A da CLT do conjunto jurídico geral que a envolve.", com a mesma preocupação sobre a tentativa do isolamento dos demais conjuntos jurídicos da CLT.

A propósito, Barbosa (2017) pondera que apesar dessa tentativa fútil de querer restringir o uso das demais leis e normas do ordenamento brasileiro, não se pode afastar a influência da Constituição Federal de qualquer ramo do Direito interno. Esta autora deixa claro que a ordem interna é que as leis inferiores à Constituição Federal devem ser 
interpretadas por ela e não o contrário, além do que todo o ordenamento jurídico é interligado, ainda que independentes.

Já Homero Silva (2017) diz que a ideia do 233-A era a de garantir que nada escape da tutela do Título II-A para que não haja lacunas ou meios dos doutrinadores e juízes criarem figuras ou subterfúgios para escapar da tarifação. Ainda que, para ele, seja impossível para a legislação manter todas as possibilidades de danos dentro de suas perspectivas, uma vez que de acordo com o autor, ninguém sabe o limite da criatividade nem da maldade humana, sendo quase impossível limitar todas as possibilidades de danos apenas em um Título de uma legislação.

Quanto à extensão do que é o dano extrapatrimonial, ele normalmente pode ser moral, estético ou de existência. Para Silva (2017) não se pode haver uma interpretação extensiva para deduzir que o dano estético esteja incluído nesse título, uma vez que não há menção expressa sobre ele. Sendo assim, ele estaria fora do rol das tarifas.

Sob outra perspectiva, Delgado e Delgado (2017) salienta que houve uma tentativa de anulação das categorias de dano extrapatrimonial, ou seja, para eles não há mais que se falar em danos estéticos ou morais, agora todos os danos não materiais seriam extrapatrimoniais, ou seja, há a perda das demais categorias.

Enquanto isso, a visão de Barbosa (2017) ao tratar de danos extrapatrimoniais, a CLT está claramente abrangendo todos os tipos de danos que ferem a alma: dano moral, estético e existencial, sendo só esse último e o moral citados expressamente.

Sobre a questão da titularidade para poder pleitear a indenização do dano, a lei trouxe que apenas o ofendido poderia fazê-lo, e isso fez com que o questionamento principal tanto de Silva quanto de Barbosa fosse justamente sobre o herdeiro do empregado falecido. Para Silva (2017) a premissa só pode ser verdadeira se não levar em conta o evento morte, que naturalmente faz com que os herdeiros tenham legitimidade para pleitear a ação; enquanto que Barbosa (2017) compreende que os herdeiros são legítimos para pleitearem a ação na Justiça do Trabalho, mas exigindo reparação dos danos sofridos por eles com a perda do ente querido.

Sobre o rol de direitos elencados nos art. 233C e 233D, para Barbosa (2017, p. 62) "Entende-se que o rol contido em ambos os artigos é meramente exemplificativo, tendo em vista a impossibilidade de o legislador prever, de forma exaustiva, todos os bens que compõe o patrimônio imaterial das pessoas físicas e jurídicas.”. Ela ainda estabelece que não pode haver uma diminuição dos direitos que a própria Constituição traz em seu artigo $5^{\circ}$. 
O ponto da solidariedade limitada, para Barbosa (2017), é simplesmente impossível de acontecer e de ser aceito pelo ordenamento jurídico. Primeiro, ela elogia a reforma ao inovar trazendo a previsão expressão da solidariedade no dano moral, porém logo começa a crítica posto que é inconcebível mensurar o quantum cada um dos ofensores foi responsável na prática, uma vez que a lesão sendo feita é resultado do conjunto de todos. Além disso, ela afirma sobre a impossibilidade de haver uma solidariedade limitada, pois o instituto da solidariedade existe para que os responsáveis possam ser cobrados integralmente pelo credor. Os devedores solidários têm a dívida in totum como responsabilidade, de modo que a critério do credor ele pode cobrá-la de apenas um deles ou de ambos, é um instituto que visa beneficiar o credor, para que ele possa garantir a reparação de seu dano sem maiores problemas. Sendo assim, não há lógica em limitar a responsabilidade do ofensor apenas por estar em uma relação de trabalho.

Os dois últimos pontos a serem tratados são a possibilidade da tarifação e o salário contratual como base, ambos estão estabelecidos no artigo 233-G, o qual traz os critérios que o juiz deverá observar na hora de estabelecer o dano extrapatrimonial. Todavia, em seu $\S 1^{\circ}$ o artigo traz a separação do dano moral em quatro tipos: leve, médio, grave e gravíssimo, sendo que cada um deles têm um limite máximo para ser valorado no artigo 233-G. ${ }^{1}$

Delgado e Delgado (2017, p. 146) trazem que a tarifação do dano moral está “[...] se esquecendo que a Constituição da República afasta o critério de tarifação da indenização do dano moral em seu artigo $5^{\circ}, \mathrm{V}$, ao mencionar, enfaticamente, a noção de proporcionalidade.".

Em entendimento semelhante, Barbosa (2017, p. 67) diz que "A tarifação do dano extrapatrimonial, além de ir contra o princípio da reparação integral disposto positivamente no artigo 944 do Código Civil, é de duvidosa constitucionalidade.”. Barbosa (2017) segue explicando três razões do porque a tarifação seria inconstitucional, sendo elas: o rompimento com a nova ordem constitucional por criar desigualdade de importância entre os direitos imateriais e os patrimoniais, já que os patrimoniais estariam regidos pela regra da reparação integral e os imateriais limitados; o conteúdo discriminatório ao atrelar o valor da reparação

\footnotetext{
1 Art. $233-\mathrm{G}[\ldots]$

$\S 1^{\text {o }}$ Se julgar procedente o pedido, o juízo fixará a indenização a ser paga, a cada um dos ofendidos, em um dos seguintes parâmetros, vedada a acumulação:

I - ofensa de natureza leve, até três vezes o último salário contratual do ofendido;

II - ofensa de natureza média, até cinco vezes o último salário contratual do ofendido;

III - ofensa de natureza grave, até vinte vezes o último salário contratual do ofendido;

IV - ofensa de natureza gravíssima, até cinquenta vezes o último salário contratual do ofendido.
}

Rev. de Direito do Trabalho e Meio Ambiente do Trabalho | e-ISSN: 2525-9857 | Porto Alegre | v. 4 | n. 2 | p. 156 - 173 |

Jul/Dez. 2018 
com a remuneração contratual do ofendido; e a não possibilidade de lei ordinária criar limites a uma norma constitucional, pois os incisos $\mathrm{V}$ e $\mathrm{X}$ do artigo $5^{\circ}$ não falam em limitação no quantum do dano moral, logo a lei infraconstitucional não poderia fazê-lo.

Para complementar sua argumentação, Barbosa (2017) traz o julgado da ADPF 130 do Supremo Tribunal Federal, STF, no qual os ministros decidiram que a Constituição Federal não recepcionou a indenização tarifada contida na lei de imprensa. Essa decisão, os desembargadores estabeleceram que a Constituição de 88 afastou a possibilidade de qualquer tarifação. Com tais argumentações, pode-se notar que a reforma, ao estabelecer a tarifação dos danos morais, não o fez consoante a ordem constitucional, pois esta traz a proporcionalidade e a razoabilidade como meios para a reparação do dano; e pelo entendimento do STF, na ADPF 130, a Constituição brasileira não teria recepcionado a ideia de limitação dos danos imateriais, deixando-os para que haja a reparação integral igual aos danos materiais.

Outro ponto questionado no artigo $233-\mathrm{G}$ é seu $\S 3^{\circ}$ determinar que a reincidência ocorre quando estiver com as partes idênticas e não com a repetição do ilícito. Essa condição de só acontecer a repetição com as mesmas partes, impossibilita a condenação de reincidência, pois conforme os dizeres de Silva $(2017$, p. 61) “[...] o que praticamente jamais acontecerá; mesmo que a gente deixe de lado o evento morte, dificilmente o mesmo empregador perseguirá o mesmo empregado [...]; o contrato já estará rompido e enterrado.”

Barbosa e Delgado e Delgado comungam do mesmo pensamento de Silva, pois da forma que a lei prevê, jamais a empresa será condenada por reincidência. O que pode gerar uma impunidade, já que a empresa poderá repedir o ilícito com qualquer outro trabalhador, desde que não seja aquele funcionário que já tenha passado por aquela situação. Além disso, em regra, esse empregado já estaria fora da empresa, pois as ações trabalhistas normalmente são interpostas na Justiça após o fim do contrato, pois os empregados têm receio de retaliação durante a vigência do contrato.

Por fim, o último tópico abordado será o fato da desigualdade de tratamento entre o empregado que ganha menor salário dos altos empregados, já que o dano moral está usando a base do salário contratado.

Para Silva (2017, p. 61) “[...] por qualquer ângulo que se observe, faz com que a dor do pobre seja menor que a do rico, independentemente da lesão [...]”.

Como se nota também nas palavras de Barbosa (2017) o parâmetro do salário contratual está garantindo que o alto empregado tem sua dor mais valorizada justamente porque ganha mais, em outras palavras, é como se sua dignidade valesse mais apenas por ter 
um rendimento maior. Levando em consideração um cálculo simples, um alto empregado que ganhe o salário de dez mil reais e tenha uma indenização de três vezes seu salário, por ser um dano leve; ganha mais que um empregado que receba salário mínimo e tenha uma indenização de dano grave no máximo, que será vinte vezes o seu salário. Como Delgado e Delgado (2017) afirmam, a desigualdade de tratamento entre os empregados já se inicia da própria base de cálculo da indenização.

\section{ANÁliSE SOBRE A LIMITAÇÃO DO DANO EXTRAPATRIMONIAL E A DIGNIDADE DA PESSOA HUMANA}

No presente tópico será analisada a questão fundamental do estudo, se há de fato uma afronta à dignidade da pessoa humana com a limitação do dano extrapatrimonial que a reforma trouxe.

O princípio da dignidade da pessoa humana está relacionado a outros princípios, como o princípio da igualdade. Nota-se que as mudanças empregadas pela Lei n. 13.467/17 em seu Título II-A estão criando diferenças sem fundamentos em valores constitucionais, revelando-se como regras discriminatórias e ilegítimas que não têm justificativa suficiente no texto constitucional.

Para compreender o que é o princípio da igualdade, vê-se as explicações de Bandeira de Melo (2010) na qual ele declara que a igualdade constitucional estabelecida no artigo $5^{\circ}$ caput é de que todos são iguais perante a lei, como explica o autor, o princípio não alcança apenas os cidadãos, como também obriga a lei a não criar medidas que descriminem as pessoas, a não ser que a diferenciação seja necessária e justa. Bandeira de Melo recorre ao ensinamento de Aristóteles de que o princípio da igualdade deve ser entendido como tratar igualmente os iguais e desigualmente os desiguais na medida de suas desigualdades.

O que se depreende das palavras de Aristóteles é que a isonomia não é necessariamente a falta de diferenciação; em verdade, a igualdade muitas vezes se alcança com critérios de diferenciação - o que a torna necessária.

A isonomia é quebrada quando há discriminação por motivos injustos ou arbitrários. Ou seja, quando a razão do ato de diferenciação não é válida juridicamente, nem moralmente, nem logicamente, é quando falta a razoabilidade entre o fato ou pessoa discriminada e o motivo pelo qual houve a discriminação. 
Por exemplo, é válido exigir que apenas mulheres possam fazer prova para policiais para presídio feminino; não há a quebra da isonomia, pois há um motivo lógico e razoável para a diferenciação feita. Por outro lado, não permitir a participação de mulheres em provas de cargos de policia geral é uma discriminação, quebrando a igualdade por não haver nenhum motivo lógico e razoável pelo quais mulheres não poderiam ser policiais.

Dessa forma, por um motivo lógico, válido e razoável pode ser limitado um direito sem que haja a quebra da igualdade entre os cidadãos que são regidos pela lei. Observa-se tal ideia nas palavras de Bandeira de Melo:

[...] as discriminações são recebidas como compatíveis com a cláusula de igualitária apenas e tão-somente quando existe um vínculo de correlação lógica entre a peculiaridade diferencial acolhida por residente no objeto, e a desigualdade de tratamento em função dela conferida, desde que tal correlação não seja incompatível com interesses prestigiados na Constituição. (2010, p.17)

Depreende-se, da citação e da explicação sobre a diferença entre discriminação e diferenciação legal, que a discriminação ocorre por três pontos: pelo fator de desigualdade escolhido, pela falta de correlação lógica entre o fator escolhido e pela disparidade estabelecida e a incompatibilidade entre a disparidade e os preceitos constitucionais.

Com tal compreensão, pode-se observar que a limitação do dano extrapatrimonial que a reforma trabalhista trouxe cria uma diferença entre o sujeito enquanto empregado e o sujeito enquanto cidadão fora da relação de emprego. O fator de desigualdade nesse caso é o fato de ser empregado, uma vez que apenas os danos morais do empregado são limitados, este fator por si só não é suficiente para que seja válida a diferenciação de seu dano moral.

A correlação lógica entre o fator de desigualdade e a disparidade não é suficiente, uma vez que pelo que se depreende da leitura de Silva (2017) o motivo que teria levado, em tese, a tarifação do dano extrapatrimonial do empregado foram as sentenças trabalhistas com valor exorbitante por danos morais decorrentes de evento morte. Primeiro, em todas as searas do Direito há valores considerados exorbitantes para os mais diversos tipos de danos morais, como também há fixação de danos irrisórios para eventos impactantes e há a negação de responsabilidade em claros eventos danosos.

Segundo, um evento como a morte de um trabalhador é algo que naturalmente extrapola as expectativas não apenas da relação de emprego, como da própria relação social; além disso, Silva diz que a mídia trata os danos morais do evento morte como exorbitantes, porém com a perda do bem mais precioso do ser humano é natural que a valoração em dinheiro deva ser alta, pois ela jamais trará a pessoa morta de volta a vida. Na visão da 
família, a indenização precisa compensar uma vida, e esse bem não tem como ser previamente tarifado e limitado.

Assim, esse tratamento trazido pela reforma trabalhista está literalmente afirmando que um trabalhador em sua relação empregatícia tem a dignidade menor que o sujeito fora da relação de trabalho. Tal situação poderia criar um caso esdrúxulo a ponto de que um trabalhador sofra um dano moral em seu trabalho e sofra o mesmo dano moral num shopping ou em qualquer lugar que frequente fora do expediente de trabalho e ganhe na Justiça Civil reparação cinco vezes maior que a da Justiça do Trabalho, apenas porque a ação lesiva tenha ocorrido dentro da relação de emprego.

E o último ponto da discriminação é a sua validade perante os preceitos constitucionais, como já foi dito no tópico anterior, a tarifação de danos é claramente contrária a Constituição Federal, já que ela não recepcionou a limitação de danos previamente, estabelecendo a regra da reparação integral mediante o uso da ponderação e da razoabilidade. Ou seja, criar a tarifação do dano extrapatrimonial para a Justiça Laboral é um ato claro de discriminação ilegítima, já que não tem justificativa mínima para sua validade e ainda é contra os ideais constitucionais da ordem jurídica brasileira.

É importante observar as lições de Bastos (2003, p. 44) “A reparação dos danos morais trabalhistas compatibiliza-se com a finalidade maior do Direito do Trabalho, na medida em que promove o respeito à dignidade do trabalhador, [...]”. Em outras palavras, o Direito do Trabalho existe justamente para garantir que a dignidade dos empregados seja respeitada dentro da relação de subordinação do emprego, o que não acontece quando se fixa numa norma o valor máximo que a dignidade de uma pessoa pode ter ao ser ferida.

É válido lembrar que além de uma fixação prévia do valor da dignidade do obreiro, da criação de uma discriminação entre o trabalhador e o cidadão fora do trabalho, a tarifação do dano extrapatrimonial ainda trouxe outra forma de discriminação ilegítima que é a base da indenização. Ao usar o salário contratual do empregado e não o salário-mínimo - como é usado na justiça - a lei já cria uma desigualdade sem motivo justo entre os empregados que recebem salários altos e os que recebem salários baixos. Novamente, é como se estabelecesse que um empregado só porque ganha mais dinheiro que outro tem sua dignidade mais importante ou com maior valor que o seu colega que recebe um salário mais parcimonioso.

Vincular previamente a dignidade humana a um valor máximo por dano é menosprezar ou, pior, admitir a existência de situações em que a dignidade humana é menos 
valiosa apenas pela pessoa se encontrar naquela situação. Admitir que um indivíduo por não ser empregado tem sua dignidade mais importante e por isso não pode ser limitada enquanto a de um trabalhador é, é admitir que no ordenamento jurídico pátrio pode haver pessoas que sejam menos merecedoras da dignidade humana ou que a dignidade deles seja menos valiosa que daqueles que não estão na sua situação.

Dessa forma, a tarifação do dano extrapatrimonial sem dúvida afronta o princípio da dignidade humana do trabalhador - bem como fere o princípio da igualdade que é basilar para uma vida digna - ao criar discriminação entre o trabalhador e o indivíduo civil sem motivação justa e suficiente e ao criar discriminação entre os altos empregados e os empregados que percebam salário-mínimo.

\section{CONCLUSÃO}

Após a análise da própria legislação e das ponderações da doutrina sobre o Título IIA da reforma trabalhista, parece claro que nos termos que a legislação foi escrita há sim a afronta ao princípio da dignidade humana do trabalhador, bem como ao princípio da igualdade, pois a lei cria diferença entre os trabalhadores no momento de estabelecer a tarifação do dano; assim, a doutrina majoritária vem se manifestando que essa discriminação é arbitrária, criando uma situação em que a dignidade dos altos empregados seja mais importante e por isso valha mais que a dos outros trabalhadores.

Observa-se, ainda, que a tarifação não é uma prática válida no ordenamento jurídico brasileiro, já que a Constituição Federal, além de não recepcionar a tarifação do dano das leis anteriores a sua vigência, não estipula limites para a reparação do dano, aplicando o princípio da reparação integral - como estabelecida no Código Civil - e havendo o balizamento da reparação pelos princípios da ponderação e razoabilidade.

Ainda, a reforma criou uma situação em que o dano moral do empregado vale menos que o dano que possa ocorrer com ele fora da relação empregatícia. Restringir a indenização do dano do cidadão apenas por estar numa relação de trabalho revela-se uma discriminação ilegítima. Logo, as tarifações do dano extrapatrimonial trabalhista ferem a dignidade do empregado, bem como a igualdade de tratamento entre um cidadão como empregado e um cidadão fora da relação de emprego.

Assim sendo, a tarifação estabelecida fere de fato a dignidade do trabalhador, bem como seu direito a tratamento igualitário entre os próprios trabalhadores e entre a classe 
trabalhadora e os demais cidadãos do país. Por essa razão, a norma que traz a limitação do dano moral trabalhista não deve ser aplicada por estar eivada de inconstitucionalidade.

\section{REFERÊNCIAS}

BASTOS, Guilherme Augusto Caputo. O dano moral no direito do trabalho. São Paulo: LTr, 2003.

BARBOSA, Fernanda Pereira. Do dano extrapatrimonial. In: ZIMMERMANN, Cirlene Luiza (coord.). Reforma trabalhista interpretada. 2. ed. rev. atual e ampl. Caxias do Sul: Plenum, 2017.

BARROSO, Luís Roberto. Curso de direito constitucional contemporâneo: os conceitos fundamentais e a construção de um novo modelo. 2. ed. São Paulo: Saravia, 2010.

A dignidade da pessoa humana no direito constitucional contemporâneo: a construção de um conceito jurídico à luz da jurisprudência mundial. Tradução Humberto Laport de Mello. Belo Horizonte: Fórum, 2014.

BRASIL. Lei N. 13.467, de 13 de julho de 2017. Altera a Consolidação das Leis do Trabalho (CLT), aprovada pelo Decreto-Lei ${ }^{\circ} 5.452$, de $1^{\circ}$ de maio de 1943, e as Leis $\mathrm{n}^{\circ} \mathrm{s} 6.019$, de 3 de janeiro de 1974, 8.036, de 11 de maio de 1990, e 8.212, de 24 de julho de 1991, a fim de adequar a legislação às novas relações de trabalho. Diário Oficial [da] União - Seção 1 14/7/2017, Página 1 Brasília, DF, 2017.

DELGADO, Maurício Godinho; DELGADO, Gabriela Neves. A reforma trabalhista no Brasil: com os comentários à lei 13.467/2017. São Paulo: LTr, 2017.

DÍAZ, Almudena Bermejo. La dificultad probatoria del daño moral: una aproximación jurisprudencial. Dissertação (Dissertação em Direito) - Universidad de la Rioja. Logroño. P. $59,2016$.

FLORES, Joaquín Herrera. A (re)invenção dos direitos humanos. Tradução de Antônio Henrique Graciano Suxberger; Carlos Rodrigo Diogo Garcia e Jefferson Aparecido Dias. Florianópolis: Fundação Boiteux, 2009.

GONÇALVES, Carlos Roberto. Direito civil brasileiro: responsabilidade civil. 13. ed. São Paulo: Saraiva, 2018.

HIERRO, Liborio L. Los derechos humanos: uma concepción de la justicia. Madrid: Marcial Pons, 2016.

MAIHOFER, Weber. Estado de derecho y dignidad humana. Traducción de José Luis Guzmán Dalbora. Montevideo: B de F, 2008.

MELLO, Celson Antônio Bandeira de. O conteúdo jurídico do princípio da igualdade. 3. ed. São Paulo: Malheiros Editores, 2010. 
MIRAGEM, Bruno Nubens Barbosa. Direito civil: responsabilidade civil. São Paulo: Saraiva, 2015.

PIOVESAN, Flávia. Direitos humanos e o direito constitucional internacional. 14. ed. rev. e atual. São Paulo: Saraiva, 2013.

Direitos Humanos e justiça internacional: um estudo comparativo dos sistemas regionais europeu, internamericano e africano. 7. Ed. Ver. Ataul. São Paulo: Saraiva, 2017.

RAMOS, André de Carvalho. Curso de direitos humanos. 5. ed. São Paulo: Saraiva, 2018.

SARLET, Ingo Wolfgang. A eficácia dos direitos fundamentais: uma teoria geral dos direitos fundamentais na perspectiva constitucional. $12 \mathrm{ed}$. rev. atual. e ampl. Porto Alegre: Livraria do Advogado, 2015.

SILVA, Homero Batista Matheus da. Comentários à reforma trabalhista: análise da lei 13.467/2017. São Paulo: Revista dos Tribunais, 2017.

TARTUCE, Flávio. Direito civil: direitos das obrigações e responsabilidade civil. V 2. 13 ed. rev. atual e ampl. Rio de Janeiro: forense, 2018. 